\title{
1.14
}

\section{A Lei de Acesso à Informação como instrumento de controle social na gestão de medicamentos do setor público}

The Information Law as a tool to control social medication menagement in the public sector

\section{Gicele T. de Almeida}

Farmacêutica Bioquímica, Especialista em Direito Sanitário e em Gestão da Assistência Farmacêutica. Farmácia de Alto Custo da Secretaria de Saúde do Distrito Federal. Brasília, Brasil.

Resumo: A completa transparência no que diz respeito a informações relevantes da gestão de medicamentos do setor público, independentemente de solicitação, e utilizando os mecanismos propiciados pelas novas tecnologias, representa tanto um interessante caminho para o efetivo controle social da administração pública, quanto uma promissora alternativa para aperfeiçoar o sistema único de saúde. Nesse sentido, a lei de acesso à informação agrega um instrumental normativo que abre novas perspectivas para a sociedade e para a gestão da administração pública.

Palavras chaves: Gestão de medicamentos; Democracia participativa; Lei de acesso à informação.

Key-words: Management of medicines; Democracy participatory; Law of Access to information.

\section{Introdução}

O estudo pretende discutir a necessidade de garantir e valorizar os espaços de manifestação da democracia participativa, focando as iniciativas orientadas à efetividade do direito à saúde no campo específico da gestão de medicamentos, afirmando a crença nos mecanismos de consolidação do regime democrático e de afirmação da cidadania.

Foi utilizada a pesquisa bibliográfica, tomando-se por base a análise de material constituído principalmente por livros, artigos científicos e monografias que permitam investigar os fenômenos relacionados ao tema, bem como a pesquisa documental através da análise da Constituição Federal e da legislação infraconstitucional relacionada a democracia participativa e ao acesso aos medicamentos, em especial as Leis $n^{\text {os }} 8.080 / 90$ e 8.142/90. 
Tomando como base para a discussão a recente Lei de Acesso à Informação, o estudo parte da análise do conceito atual e ampliado de saúde, formulado a partir das discussões produzidas na VIII Conferência Nacional de Saúde de 1986, no contexto do processo de redemocratização do país, no âmbito do movimento da Reforma Sanitária.

Por fim, analisam-se alguns dos ganhos possíveis do efetivo controle social da gestão de medicamentos pelo setor público, no contexto da democracia participativa.

\section{Direito à Saúde}

O grande passo para a consolidação dos direitos humanos foi dado no contexto das revoluções liberais do século XVIII. Bonavides (2002) assinala que a Revolução Francesa de 1789 ao proclamar os ideais de "Liberdade, Igualdade e Fraternidade" deu origem aos propósitos igualitários.

É com base no princípio da igualdade que passam a serem reconhecidos como direitos humanos os direitos sociais, que se realizam pela execução de políticas públicas, destinadas a garantir o amparo e a proteção social aos mais fracos e mais pobres; ou seja, aqueles que não dispõem de recursos próprios para viver dignamente (Comparato, 1999).

O conceito ampliado de saúde surge na década de 1940, no contexto das tragédias e do flagelo provocado pelas duas grandes guerras, tendo por objetivo resgatar a dignidade da pessoa humana e melhorar a qualidade de vida das pessoas.

Como resultado das discussões desse período, a Organização Mundial de Saúde (OMS, 1946) estabeleceu o conceito de saúde como sendo a resultante de "um estado de completo bem-estar físico, mental e social, e não consiste apenas na ausência de doença ou enfermidade".

No Brasil, o conceito atual e ampliado de saúde foi formulado a partir das discussões produzidas na VIII Conferência Nacional de Saúde de 1986, sendo resultante de mobilizações que ocorreram durante o processo de redemocratização do país, no âmbito do movimento da Reforma Sanitária.

A saúde representa um direito humano fundamental, pois está ligada à vida, sendo condição essencial de sua existência. A vida é o maior bem do ser humano, pois sem ela os demais bens não possuem significado. No Brasil a positivação da 
saúde como direito fundamental se deu na Constituição Federal de 1988, nos artigos 6ำ e 196.

Sua efetivação tem se realizado através de políticas públicas desenvolvidas pelo Estado que buscam diminuir as desigualdades sociais, organizando as funções públicas para promoção, proteção e recuperação da saúde, tanto no aspecto individual quanto coletivo.

O Sistema Único de Saúde (SUS), desenvolvido no plano legislativo através da Lei Orgânica da Saúde - Lei no 8.080/90 e Lei no 8.142/90 -, teve sua estrutura e modelo organizado visando efetivar o direito fundamental à saúde. $\mathrm{E}$, de acordo com o art. 2ำ ao Estado cabe garantir as condições necessárias para o exercício desse direito mediante serviços e ações organizados para esse fim.

\section{0 medicamento no contexto do direito à saúde}

Com previsão constitucional (arts. 196 a 200), o SUS teve as linhas gerais de sua estrutura regulamentadas por meio da Lei Orgânica da Saúde - Lei nº 8.080/90 que em seu artigo $6^{\circ}$, I, "d", estabelece, dentre outras atribuições, a responsabilidade pela execução de ações de assistência farmacêutica:

Art. 6ํㅡㄹ Estão incluídas ainda no campo de atuação do Sistema Único de Saúde-SUS:

I - a execução de ações:

$[\ldots]$

d) de assistência terapêutica integral, inclusive farmacêutica.

Portanto, a saúde como um direito fundamental, a partir das disposições constitucionais, também compreende a assistência farmacêutica que, desse modo, está inserida no complexo de atribuições do Sistema Único de Saúde.

Assim, o acesso aos medicamentos, além de representar uma necessidade vital para muitos, é um componente fundamental na atenção à saúde, cujo acesso encontra respaldo na Constituição Federal e na Lei Orgânica da Saúde.

Nesse contexto, relevante assinalar o princípio da integralidade, pelo qual, segundo Santa'Ana et al. (2011), a assistência farmacêutica deve estar articulada com o serviço de saúde, compreendendo tanto um dever do Estado quanto um direito dos cidadãos que, por vezes, buscam a satisfação de suas necessidades por meio do Poder Judiciário. Esse processo gera o fenômeno conhecido por Juidicialização da Saúde. 


\section{Gestão de medicamentos e políticas públicas}

\subsection{Política Nacional de Medicamentos}

Visando garantir a integralidade da assistência farmacêutica, dentro do SUS, o Ministério da Saúde desenvolve uma série de estratégias para organizar e sistematizar a complexa logística que a demanda por medicamentos representa no contexto do direito à saúde. Essa sistematização se concretiza na forma de políticas públicas que permitam à população o efetivo acesso aos medicamentos.

A Portaria no 3.916/MS/GM/1998 determina a adoção da relação de medicamentos essenciais (RENAME) que esta embasada em critérios epidemiológicos da população, e determina que os mesmos estejam continuamente disponíveis. Dessa forma, fez-se necessária a reorientação da assistência farmacêutica, incluindo as três esferas governamentais, com a finalidade de descentralizar a gestão, viabilizando o acesso aos medicamentos e aperfeiçoando a distribuição, com a redução de custos (Brasil, 1998).

Para alcançar estes objetivos, as diferentes esferas governamentais devem atuar de forma articulada e em cooperação técnica e financeira viabilizando o acesso da população aos medicamentos.

Aproximando a abordagem ao objeto em análise, assinale-se que há estudos indicando que é significativo o número de ações judiciais individuais que tem por fim justamente sanar problemas relacionados ao desabastecimento de medicamentos que integram a RENAME. Isso, por si só, recomenda o aprimoramento dos mecanismos de transparência na divulgação de informações relacionadas com o processo de programação e aquisição de medicamentos.

\subsection{Política Nacional de Assistência Farmacêutica}

Com a finalidade de dar seguimento a Política Nacional de Medicamentos o Conselho Nacional de Saúde aprovou a Política Nacional de Assistência Farmacêutica - PNAF, por meio da Resolução no 338/2004, sendo parte integrante da Política Nacional de Saúde.

A Resolução estabelece que a Assistência Farmacêutica esteja incluída como componente estratégico para a garantia do acesso e da equidade às ações de saúde e determina que a mesma esteja presente nos diferentes níveis de complexidade dentro do SUS (Brasil, 2004). 
A PNAF esta fundamentada na descentralização das ações de saúde que devem ser articuladas e pactuadas entre os entes governamentais e leva em conta a RENAME e sua atualização periódica, estratégia já estabelecida pela Política Nacional de Medicamentos. Da mesma forma, estimula ações que visem o desenvolvimento de tecnologias que venham a atender as necessidades e prioridades dentro do SUS e estabeleçam políticas públicas voltadas para a vigilância sanitária a fim de garantir produtos seguros, eficazes e de qualidade, além de estimular a qualificação de recursos humanos para as ações de saúde (Brasil, 2004).

Dessa forma, a Política Nacional de Medicamentos e de Assistência Farmacêutica deve ser harmonizada, estabelecendo os rumos para uma gestão mais eficiente da assistência farmacêutica.

A Portaria nº 176/2006 do Ministério da Saúde determinou as novas formas de alocação de recursos federais propostas pelo Pacto de Gestão do SUS. Estabeleceu um bloco de recursos próprios para o financiamento da assistência farmacêutica, além de determinar o agrupamento dos programas em componentes da Assistência Farmacêutica financiados pelos três gestores do SUS (Brasil, 2006).

O bloco da assistência farmacêutica, destinado à aquisição de medicamentos para a oferta à população em serviços ambulatoriais do SUS está dividido em três componentes, financiado pelos diferentes entes de gestão, de acordo com o grupo em que o medicamento estará alocado:

a) Básico: composto por medicamentos, incluídos na RENAME, e insumos essenciais destinados ao atendimento dos agravos prevalentes e prioritários da Atenção Básica, sendo adquiridos pelo Ministério da Saúde (Programa Saúde da Mulher e Insulinas) e pelos Estados e Municípios conforme estipulado na pactuação bipartite, sendo financiado pelas três esferas de gestão e cuja forma de aquisição deve ser pactuada na comissão bipartite (Brasil, 2010).

b) Estratégico: constituído por medicamentos dispensados para programas específicos do Ministério da Saúde como, por exemplo, de controle da aids e da tuberculose, cuja aquisição e financiamento são exclusivos do Ministério da Saúde.

c) Especializado: composto por medicamentos que buscam garantir a integralidade do tratamento medicamentoso, em nível ambulatorial, cujas linhas de cuidados estão definidas em Protocolos Clínicos e Diretrizes Terapêuticas estabelecidos pelo Ministério da Saúde. O Componente Especializado esta dividido 
em grupos de medicamentos cuja aquisição e financiamento são organizados de forma distinta em: Medicamentos sob responsabilidade da União (Grupo 1A e 1B); sob responsabilidade dos Estados e Distrito Federal (Grupo 2); e sob responsabilidade dos Municípios e Distrito Federal ( Grupo 3).

Conforme avaliação realizada pelo Departamento de Assistência Farmacêutica do Ministério da Saúde, quase $60 \%$ dos municípios pactuaram a transferência de recursos financeiros federais e estaduais para o Fundo Municipal de Saúde (Brasil, 2008). Dessa forma, a gestão torna-se local e a responsabilidade pela aquisição dos medicamentos do Componente Básico passa a ser do município.

A sofisticada divisão de atribuições e de responsabilidades indica o desafio e a complexidade operacional do sistema - tanto no aspecto da gestão quanto no que diz respeito aos encargos financeiros - entre os entes.

\subsection{Aspectos gerais da gestão de medicamentos}

No que diz respeito à gestão de medicamentos, há informações cujo conhecimento seria um importante instrumento para o controle social sobre a gestão pública, desde que, é claro, estejam disponíveis de forma objetiva, transparente e em linguagem de fácil compreensão, tal como estabelece a Lei de Acesso à informação. Dentre as informações pertinentes, destacam-se:

a) consumo médio mensal (CMM): refere-se à média dos consumos mensais de cada produto num certo período de tempo, permitindo a previsão de compras que garantam a manutenção de estoques mínimos;

b) estoque mínimo ou de segurança (EMn): quantidade de cada item que deverá ser mantida como reserva para garantir a continuidade do atendimento em caso de ocorrências não previstas, como a elevação brusca no consumo ou o atraso na entrega do produto;

c) prazo de abastecimento (PA): período compreendido entre a solicitação e a chegada do produto, estando compreendido o tempo gasto desde a emissão do pedido até a disponibilidade do produto para a dispensação nas unidades de saúde;

d) dados referentes à licitação pública: modalidade de licitação para o processo de compra com especificações dos fornecedores que participaram do processo ou registrando a ausência desses, quando for o caso, e também informações referentes à dispensa de licitação. São relevantes, também, informações que tratam do prazo de 
entrega, quantidade requerida conforme o tempo que se pretende abranger com o processo licitatório.

Destacam-se também dados relativos ao fluxo das atividades operacionais do processo de compra com atribuições dos setores responsáveis por cada etapa dando transparência a gestão e permitindo a sociedade uma melhor compreensão das atividades envolvidas para a aquisição de medicamentos cuja compra é descentralizada.

Assim, o conhecimento das informações e a possibilidade de monitoramento viabilizariam o efetivo acompanhamento da gestão, e dos estoques, constituindo uma poderosa ferramenta para o controle social de uma área tão sensível quanto importante desse vital setor estatal.

Indo além das questões burocráticas da logística da gestão de medicamentos pelo Setor Público, é oportuno referir à observação de Alves (2008) no sentido de que o reconhecimento da saúde como direito de todos e dever do Estado representa, ao menos no campo das possibilidades, um rico espaço para que a sociedade civil com destaque para os movimentos sociais - que, de forma articulada, podem apresentar-se como protagonistas na conquista de novos direitos. Nesse sentido, referindo à abordagem de Arato e Cohen (1994), a autora registra a construção de novos espaços públicos para o exercício da cidadania.

\section{A gestão de medicamentos e o direito à informação}

\subsection{0 controle social na gestão de medicamentos}

Conforme observa Alves (2008), abordando a participação social noutro contexto, a participação no processo de tomada de decisão requer a reconfiguração do papel do cidadão, extrapolando os estreitos limites da participação eleitoral.

A autora assinala que o processo representa "uma desconstrução da concepção hegemônica da via representativa como único modelo capaz de conduzir à estabilidade do sistema democrático" (Alves, 2008, p. 71). Tudo isso, sem ignorar os enormes desafios de conjugar mecanismos de democracia direta e semidireta, tendo presente que "o objetivo da participação cidadã não é negar o papel do Estado ou de suas instituições, e sim redefini-los" (Alves, 2008, p. 71).

No âmbito estritamente constitucional, o compromisso da ordem jurídica e da sociedade brasileira com a ampla publicidade das ações estatais vem sendo afirmado 
pelo Supremo Tribunal Federal. O Ministro Celso de Mello cunhou uma assertiva reproduzida em diversos julgados - que bem ressalta a força desse comando:

o novo estatuto político brasileiro - que rejeita o poder que oculta e que não tolera o poder que se oculta - consagrou a publicidade dos atos e das atividades estatais como valor constitucional a ser observado, inscrevendo-a, em face de sua alta significação, na declaração de direitos e garantias fundamentais que a Constituição da República reconhece e assegura aos cidadãos (sem destaques no original). (STF, 2009)

Essa é a obrigação e o desafio do administrador à luz dos comandos constitucionais que asseguram aos administrados o direito de conhecer e a prerrogativa de participar do processo de gestão. Surge uma importante limitação ao exercício do poder, que não pode ser operacionalizado de forma oculta.

Eventual atuação de modo diverso distancia-se do modelo que convém a regimes democráticos em que, como registra Bobbio (2000), não há espaço possível reservado ao mistério.

$\mathrm{Na}$ questão central desse estudo - a participação popular na gestão de medicamentos - invoca-se as lições de Bonavides (2008) que afirma não bastar à mera adoção de um sistema democrático. Deve-se dinamizar a democracia por meio dos mecanismos de participação popular.

Em outra passagem, Bonavides (2008, p. 509-510) enfatiza que a participação é o lado dinâmico da democracia. Assinala que "a vontade atuante que, difusa ou organizada, conduz no pluralismo o processo político à racionalização, produz o consenso e permite concretizar, com legitimidade, uma política de superação e pacificação de conflitos".

\subsection{A Lei de Acesso à Informação e o controle social na gestão de medicamentos}

Aprofundando a discussão acerca de necessidade de garantir e valorizar os espaços de manifestação da democracia participativa, de maneira ampla, assistiu-se, recentemente, o surgimento de um instrumento normativo infraconstitucional que pode representar importante impulso às iniciativas orientadas à efetividade do direito à saúde, por meio da democracia participativa, também no campo específico da gestão de medicamentos.

Registre-se que escapa aos propósitos desse estudo o aprofundamento da discussão quanto a outros aspectos da Lei de Acesso à Informação, como àqueles 
referentes ao controle da corrupção, tal como consta na Exposição de Motivos do Projeto de Lei que deu origem à Lei $\mathrm{n}$ ํ 12.527/2011:

A garantia do direito de acesso à informaccões públicas como regra geral é um dos mecanismos da consolidação dos regimes democráticos. O acesso a informação pública, além de indispensável ao exercício da cidadania, constitui um dos mais fortes instrumentos de combate á corrupção. (sem destaques no original) (Brasil, 2011)

O fragmento transcrito da Exposição de Motivos sinaliza para as expectativas do instrumento como mecanismo de consolidação do regime democrático e de afirmação da cidadania.

Nesse sentido, a regra é a transparência e o pleno acesso às informações, somente sendo admitido o sigilo, "mediante decisão devidamente fundamentada que indique o prazo para a interposição de recurso e a autoridade que o decidirá" (Brasil, 2011). Ainda assim, a restrição ao acesso "somente será permitida em caso de informações pessoais ou imprescindíveis à segurança da sociedade e do Estado" (Brasil, 2011).

Ao final da Exposição de Motivos, refere-se o direito de acesso à informação como direito fundamental, sendo um dos requisitos para que o Brasil aprofunde a democracia participativa, "em que não haja obstáculos indevidos à difusão das informações públicas e a sua apropriação pelos cidadãos” (Brasil, 2011).

É necessário registrar, também, que a Lei nํ⒓527/2011 somente entrou em vigor em 16 de maio de 2012. Assim, ainda são escassos os estudos acerca do seu alcance, limitações e possibilidades. Por isso mesmo, recorreu-se à Exposição de Motivos, onde estão expressas as intenções do legislador.

Também é importante referir que a Lei apenas regulamenta um direito

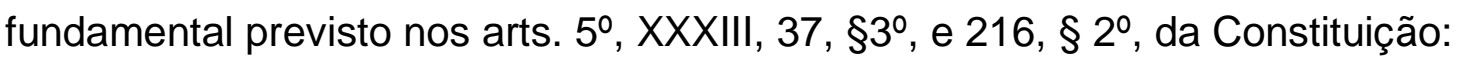

Art. 5 XXXIII - todos têm direito a receber dos órgãos públicos informações de seu interesse particular, ou de interesse coletivo ou geral, que serão prestadas no prazo da lei, sob pena de responsabilidade, ressalvadas aquelas cujo sigilo seja imprescindível à segurança da sociedade e do Estado;

Art. 37, § $3^{\circ}$ - A lei disciplinará as formas de participação do usuário na administração pública direta e indireta, regulando especialmente:

Art. 216, $\S 2^{\circ}$ - Cabem à administração pública, na forma da lei, a gestão da documentação governamental e as providências para franquear sua consulta a quantos dela necessitem.

O direito fundamental ao acesso a informação pode ser exercido contra todos os entes federados: União, Estados e Municípios; assim como órgãos públicos, 
autarquias, fundações, empresas públicas e sociedades de economia mista (art. $1^{\circ}$ da Lei $\left.\mathrm{n}^{0} 12.527 / 2011\right)$.

Além disso, a Lei define diretrizes (art. $3^{\circ}$ ) cuja invocação, no caso da gestão de medicamentos, pode ser de vital importância para o funcionamento e/ou aperfeiçoamento do Sistema Único de Saúde: I - publicidade como regra geral; II divulgação de informações de interesse público, independentemente de solicitação; III - utilização de meios de comunicação viabilizados pela tecnologia da informação; IV fomento ao desenvolvimento da cultura de transparência na administração pública; e V - desenvolvimento do controle social da administração pública.

A conjugação dessas diretrizes, expressas no texto da Lei, alimenta a hipótese que anima esse estudo. Trabalha-se com a hipótese de que a ampla transparência no que diz respeito a informações relevantes da gestão medicamentos, independentemente de solicitação, utilizando os mecanismos propiciados pelas novas tecnologias, viabilize o efetivo controle social da administração pública.

Ainda que não se tenha, por ora, o propósito de investigar mais profundamente os desdobramentos, as eventuais dificuldades e os benefícios que essa proposta apresenta, é fora de dúvidas que haveria maiores dificuldades em omitir as falhas ou interrupções na disponibilidade de medicamentos caso a gestão fosse transparente, como impõe a Lei. As desculpas fáceis, assim como o simples silêncio, poderiam ser contestados pelos cidadãos usuários - controle social da administração pública.

Mais do que isso, não é necessário maior esforço intelectual para constatar que a possibilidade de acompanhamento, de forma transparente, da logística de aquisição e de gestão dos estoques, em tempo real, desde a fase de planejamento, viabilizaria a efetiva possibilidade de que os cidadãos, de forma individual ou coletiva, exercessem concretamente as possibilidades da democracia participativa, tal como defendido por Bonavides (2008).

Embora a questão, pelas restrições desse estudo, não vá ser aprofundada aqui, registre-se que essa vertente também apresentaria evidentes desdobramentos positivos noutro campo muito caro ao Direito Sanitário - judicialização da saúde -, na medida em que a possibilidade de conhecimento prévio de falhas de gestão, como por exemplo, no processo planejamento de aquisição e/ou organização de estoques de medicamentos, viabilizaria ações coletivas - políticas, administrativas e/ou 
judiciais - na implementação de políticas públicas, reduzindo a necessidade das ações judiciais individuais que tanto preocupam os que se debruçam sobre o tema.

Noutra direção, afastando-se de uma posição exclusivamente crítica em relação ao gestor, que pode estar agindo de forma zelosa, também pode ser vislumbrada a oportunidade de que sejam reconhecidas dificuldades efetivas ao suprimento de medicamentos, pelas mais variadas razões, tais como: ausência de interesse dos fornecedores; obstáculos de ordem técnica; restrição na fabricação; ou falta de insumos para a produção.

\section{Considerações finais}

O amplo conceito do direito à saúde, como um direito fundamental, positivado a partir das disposições constitucionais, também compreende a assistência farmacêutica que, desse modo, está inserida no complexo de atribuições do Sistema Único de Saúde. Assim, a assistência farmacêutica e os medicamentos são parte integrante do amplo conceito de direito à saúde.

Nesse sentido a Relação Nacional de Medicamentos Essenciais - RENAME serve de base para a sistematização e racionalização do processo de uso e aquisição dos medicamentos dentro do SUS. A lista reorientou a assistência farmacêutica, sistematizou a gestão e trouxe um modelo compartilhado entre os três entes governamentais, facilitando o acesso da população aos medicamentos.

A complexa e sofisticada divisão de atribuições e de responsabilidades indica o desafio e a complexidade operacional do sistema - tanto no aspecto da gestão quanto no que diz respeito aos encargos financeiros - entre os entes.

Desse modo, a maior ou menor efetividade do direito à saúde está a depender das possibilidades do efetivo controle social e da participação da comunidade na gestão de medicamentos do Setor Público, tendo como pano de fundo as disposições constitucionais, a Lei Orgânica da Saúde e a Lei de Acesso à Informação.

No aspecto conceitual, a participação social encontra suporte nas correntes de entendimento que valorizam a democracia participativa, das quais se extrai a concepção de Estado democrático-participativo, dotado de efetiva legitimidade, no qual o povo chegue ao poder, "a sociedade à regeneração e o Estado e a Nação, abraçados com a cidadania, à execução e observância do contrato social" (Bonavides, 2008, p. 23). 
Nesse contexto, a recente Lei de Acesso à Informação apresenta-se como inspirador instrumento normativo que pode impulsionar as iniciativas orientadas à efetividade do direito à saúde, por meio da democracia participativa, também no campo específico da gestão de medicamentos.

Como consequência direta da transparência nas informações e da efetiva participação social é possível visualizar, inclusive, a redução da necessidade das ações judiciais individuais em busca de medicamentos, por meio de ações políticas, administrativas ou judiciais, preventivas e coletivas.

Assim, sustenta-se que a ampla transparência no que diz respeito a informações relevantes da gestão de medicamentos, independentemente de solicitação, e utilizando os mecanismos propiciados pelas novas tecnologias, viabilizaria o efetivo controle social da administração pública, impedindo, ao menos nessa área da vida social, que a democracia se transforme em uma concha vazia, tal como diagnosticou Nelson Mandela: "Democracia com fome, sem educação e saúde para a maioria, é uma concha vazia".

\section{Referências}

ALVES, Sandra Mara Campos. Processo de participação da sociedade civil nas consultas públicas realizadas pela Agência Nacional de Vigilância Sanitária - Anvisa: (2000 - 2006). Tese (Mestrado). Brasília, Universidade de Brasília, 2008.

ARATO, Andrew e COHEN, Jean. Sociedade Civil e teoria política. Em: AVRITZER, Leonardo (Coor.). Sociedade Civil e Democratização. São Paulo: Del Rey, 1994. 308 p.

BOBBIO, Norberto. O futuro da democracia. São Paulo: Paz e Terra, 2000.

BONAVIDES, Paulo. Curso de Direito Constitucional. São Paulo: Malheiros, 2002.

BONAVIDES, Paulo. Teoria Constitucional da democracia participativa (por um direito constitucional de luta e resistência, por uma nova hermenêutica, por uma repolitização da legitimidade). São Paulo: PC, 2008.

BRASIL. Constituição da República Federativa do Brasil de 5/10/1988. Brasília: Senado Federal, 2009.

BRASIL. Controladoria Geral da União. Exposição de Motivos de Projeto de Lei, Brasília, 2009. Disponível em: http://www.cgu.gov.br/ acessoainformacao/materiaisinteresse/exposicao-motivos-projeto-lei-acesso-informacao.pdf . Acesso em $10 / 11 / 2012$.

BRASIL. Ministério da Saúde. Portaria GM no 3.916/1998. Disponível em: http://www.anvisa.gov.br/legis/consolidada/portaria 3916 98.pdf . Acesso em $7 / 10 / 2012$. 
BRASIL. Lei $n^{\circ}$ 8.080, de 19 de setembro de 1990. Dispõe sobre as condições para a promoção, proteção e recuperação da saúde, a organização e o funcionamento dos serviços correspondentes e dá outras providências. (Lei Orgânica da Saúde). Diário Oficial da República Federativa do Brasil, Brasília, DF, 20 set. 1990. Disponível em: http://www.planalto.gov.br/ ccivil_03/leis/L8080.htm . [data de consulta: 5 nov. 2012].

BRASIL. Lei $n^{\circ}$ 8.142, de 28 de dezembro de 1990. Dispõe sobre a participação da comunidade na gestão do Sistema Único de Saúde (SUS\} e sobre as transferências intergovernamentais de recursos financeiros na área da saúde e dá outras providências. Disponível em: http:www.planalto.gov.br/ccivil_03/leis/L8142.html [data de consulta: 18 nov. 2012].

BRASIL. Supremo Tribunal Federal. MS 28027- DF, Min. Rel. CELSO DE MELLO. Julgamento 30/06/2009. Publicação 03/08/2009. Brasília. Disponível em: http://www.stf.jus.br/portal/constituicao/artigoBd.asp?item=2126 . Acesso em 7/11/2012.

BRASIL. Ministério da Saúde. Relação Nacional de Medicamentos Essenciais RENAME, Brasília, 2010. Disponível em: http://portal.saude.gov.br/portal/arquivos /pdf/rename2010final.pdf . Acesso em 10/11/2012.

COMPARATO, Fábio Konder. A Afirmação Histórica dos Direitos do Homem. São Paulo: Saraiva, 1999.

SANT'ANA, João Maurício Bramabati [et al.]. Racionalidade Terapêutica: elementos médico-sanitários nas demandas judiciais de medicamentos. Revista de Saúde Pública, 45(4):714-721, 2011. 